Check for updates

The BMJ

Cite this as: $B M / 2022 ; 376: 0110$ http://dx.doi.org/10.1136/bmi.0110 Published: 14 January 2022

\section{Covid-19: Omicron variant is linked to steep rise in hospital admissions of very young children}

\author{
Ingrid Torjesen
}

Hospital admissions of children under 1 year old have risen steeply, coinciding with transmission of the omicron variant, show preliminary data presented to the government's SAGE committee. ${ }^{1}$

The data, from the Covid-19 Clinical Information Network (CO-CIN) study, show that the proportion of children admitted to hospital with covid-19 who were aged under 1 was $42.2 \%$ in the four week period studied (14 December 2021 to 12 January 2022), much higher than earlier in the pandemic.

Under 1s made up $32.9 \%$ of children admitted during the first wave (January to August 2020), 30.4\% in the second wave (September 2020 to April 2021), and $30.2 \%$ when delta was the most prevalent variant (May 2021 to 13 December 2021).

The alpha and delta variants were also associated with increased cases in children, raising concerns that children would be more vulnerable to these variants and would become sicker. But this turned out not to be the case, said Calum Semple, professor of child health and outbreak medicine at the University of Liverpool, who presented the data at a Science Media Centre briefing on 13 January 2021.

And the indications are that children admitted to hospital with omicron are even less sick, as they require less support than children admitted earlier in the pandemic and are discharged earlier. Oxygen use by children aged under 1 admitted in the past four weeks for whom data are available was $12 \%$, compared with $22.5 \%$ in the first wave of the pandemic. Admission to intensive care was 9.9\% ( $v$ $14 \%)$, use of mechanical ventilation was $2 \%(v 5.8 \%)$, use of non-invasive ventilation was $2 \%(v 7.2 \%)$, and mean length of stay was 1.7 days ( $v 6.6$ days).

\section{Other viruses}

A rapid review by NHS England of 55 babies admitted to hospital with omicron found that most were aged under 3 months and that around half were admitted for observation and received no treatment, said Russell Viner, professor of child and adolescent health at University College London. "Clinically, this picture is incredibly reassuring," he said.

Camilla Kingdon, president of the Royal College of Paediatrics and Child Health, said, "As paediatricians, we are accustomed to having busy winters where we see lots of particularly under 1s, typically, with high fevers, often with some kind of respiratory distress."

She noted an increase in babies testing positive for omicron but lots of other respiratory viruses also circulating. "The presentation of these babies very much fits in with a mix of what we would expect to see in a busy winter in the UK," she said.
Kingdon added that South Africa had also seen a sharp rise in hospital admissions of under $5 \mathrm{~s}$ associated with omicron but that most had not needed supportive care and had required a shorter length of stay.

Data from the US Centers for Disease Control and Prevention (CDC) show that in the week from 26 December 2021 to 1 January 2022 more than five in every 100 ooo children under 5 who were admitted to hospital were infected with covid-19, nearly double the rate reported in early December before the omicron variant began to take hold. The CDC explained that many children were admitted with covid-19 rather than because of it. ${ }^{2}$ Clarification: We amended paragraph 2 of this article on 17 January 2022
to clarify ambiguous phrasing about the proportion of children admitted to hospital.

Scientific Advisory Group for Emergencies. CO-CIN: Child admissions and severity by epoch CO-CIN update January 2022, 6 January 2022. 14 Jan 2022. https://www.gov.uk/government/publications/co-cin-child-admissions-and-severity-by-epoch-co-cin-update-january-2022-6-january-2022 McNiff S. Covid hospitalizations rising in kids too young for vaccine. US News. 13 Jan 2022. https://www.usnews.com/news/health-news/articles/2022-01-13/covid-hospitalizations-rising-in-kids-too-young-for-vaccine

This article is made freely available for personal use in accordance with BMJ's website terms and conditions for the duration of the covid-19 pandemic or until otherwise determined by BMJ. You may download and print the article for any lawful, non-commercial purpose (including text and data mining) provided that all copyright notices and trade marks are retained. 